\title{
Capitation and enhanced fee-for-service models for primary care reform: a population-based evaluation
}

\author{
Richard H. Glazier MD MPH, Julie Klein-Geltink MHSc, Alexander Kopp BA, Lyn M. Sibley PhD
}

An abridged version of this article appeared in the May 26, 2009, issue of CMAJ and is available at www.cmaj.ca/cgi/content/full/180/11/E72/DC2.

$\infty$ See related commentary by Starfield, available at www.cmaj.ca/cgi/content/full/180/11/1091.

\section{ABSTRACT}

Background: Primary care reform in Ontario, Canada, included the initiation of a blended capitation model in 2001-2002 and an enhanced fee-for-service model in 2003. Both models involve patient rostering, incentives for preventive care and requirements for after-hours care. We evaluated practice characteristics and patterns of care under both models.

Methods: Using administrative data, we identified physicians belonging to either the capitation or the enhanced fee-for-service group throughout the period from Sept. 1, 2005, to Aug. 31, 2006, and their enrolled patients. Practices were stratified by location (urban v. rural). We compared the groups in terms of practice characteristics and patterns of care, including comprehensiveness of care, continuity of care, after-hours care, visits to the emergency department and uptake of new patients.

Results: Patients in the capitation and enhanced fee-forservice practices had similar demographic characteristics. Patients in capitation practices had lower morbidity and comorbidity indices. Comprehensiveness and continuity of care were similar between the 2 groups. Compared with patients in enhanced fee-for-service practices, those in capitation practices had less after-hours care (adjusted rate ratio $[R R] 0.68,95 \%$ confidence interval $[\mathrm{Cl}] 0.61-0.75)$ and more visits to emergency departments (adjusted RR 1.20, $95 \% \mathrm{Cl} 1.15-1.25)$. Overall, physicians in the capitation group enrolled fewer new patients than did physicians in the enhanced fee-for-service group (37.0 v. 52.0 per physician); the same was true of new graduates (60.3 v. 72.1 per physician).

Interpretation: Physicians enrolled in the capitation model had different practice characteristics than those in the enhanced fee-for-service model. These characteristics appeared to be pre-existing and not due to enrolment in a new model. Although the capitation model provides an alternative to fee-for-service practice, its characteristics should be the focus of future policy development and research.

Une version française de ce résumé est disponible à l'adresse www.cmaj.ca/cgi/content/full/180/11/E72/DC1

CMAJ 2009;180(11):E72-E81
$\mathrm{P}$ rimary health care is facing a number of serious challenges internationally, with questions being raised about whether it will even survive in some settings. ${ }^{1}$ Fundamental issues include shortages in human resources and maldistribution of physicians; dissatisfaction on the part of providers and patients; gaps between guideline-recommended care and provided care; and a preference of trainees to choose specialty careers. Close to 4 million Canadians do not have a family physician, and more than 2 million report difficulties in accessing routine or ongoing care at any time of day as well as immediate care for minor health problems at any time of day. ${ }^{2}$ Canadians in rural areas face geographic barriers to care, fewer available health care professionals than in urban areas and higher rates of disease. ${ }^{3}$

In response to these challenges, policy-makers in Canada and elsewhere are considering or are implementing interdisciplinary teams, new organizational structures, new governance and reimbursement models, requirements for after-hours care, provision of after-hours advice by telephone, electronic health records and other information technology, and pay-forperformance initiatives. Many of these directions are incorporated in the Medical Home concept in the United States ${ }^{4}$ and in the Quality and Outcomes Framework in the United Kingdom. ${ }^{5}$ Although there is evidence for the effectiveness of some of these initiatives, most have not been rigorously evaluated. Reimbursement models, perhaps the best-studied aspect of primary care reform, seem to influence some aspects of physician behaviour. However, there is a lack of evidence about their ultimate impact on patient outcomes. ${ }^{6}$

In Ontario, Canada, a blended capitation model called the Family Health Network was introduced in 2001-2002. An enhanced fee-for-service blended model called the Family Health Group was introduced in 2003. These models rapidly attracted physicians. By 2006, they were the most common models of care in Ontario, exceeding the straight fee-for-service plan.

Physicians are free to select one of the models or remain in the straight fee-for-service plan. Many make decisions based

From the Institute for Clinical Evaluative Sciences (Glazier, Klein-Geltink, Kopp, Sibley), Toronto, Ont., St. Michael's Hospital Centre for Research on Inner City Health (Glazier), Toronto, Ont., the Department of Family and Community Medicine and the Dalla Lana School of Public Health (Glazier), University of Toronto, Toronto, Ont. 
on a free revenue analysis that uses their previous billings to project their income under the capitation model. Our evaluation, involving more than 500 physicians and close to half a million patients under the capitation model, is therefore an examination of one of the world's largest short-term voluntary shifts from fee-for-service to capitation. Our objective was to evaluate practice characteristics and patterns of care under the capitation model, including comprehensiveness, continuity, after-hours care, visits to the emergency department and uptake of unattached patients. We used practices in the enhanced fee-for-service model as a contemporaneous comparison group.

\section{Methods}

\section{Setting}

Ontario is Canada's largest province, with a population in

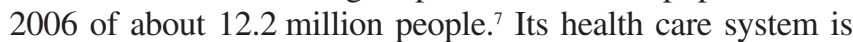
provincially run according to the principles of the Canada Health Act, ${ }^{8}$ the basis of which is to "facilitate reasonable access to health services without financial or other barriers." Accordingly, necessary physician and hospital services are fully covered with no copayments or deductibles. Prescription medications are not universally covered except for people 65 years of age and older and people receiving welfare or disability coverage. The province had about 22000 practising physicians in 2006, about half of whom were specialists. ${ }^{9}$ General internists typically have referral- and hospital-based practices in Ontario, but many pediatricians provide primary care, especially those in larger urban centres.

\section{Models}

The main difference between the models is how physicians are reimbursed. In the capitation model, the majority of reimbursement is through age- and sex-adjusted capitation payments. In the enhanced fee-for-service model, physicians receive the majority of payment through fee-for-service billing. Another difference is patient enrolment, which is mandatory only in the capitation model. Many of the other features of these models are similar and are described in detail in Table 1.

\section{Study design and population}

We created a cohort of physician groups that were in existence from Sept. 1, 2005, to Aug. 31, 2006. Study physicians were those who were consistently part of the same capitation or enhanced fee-for-service group during that period. Study patients were those who were enrolled to these physicians during the study period. Before analysis of the data, all patient and provider identifiers were removed and replaced with unique encrypted numbers.

We examined the characteristics of the study physicians and patients in each model, stratified by geographic location according to the Rurality Index of Ontario..$^{10}$ The strata used were major urban (index 0-9), non-major urban (10-44) and rural $(\geq 45)$. The Rurality Index ranges from 0 to 100 and is a policyrelevant measure used to assign incentive payments to physicians who practise in communities with an index of 45 or higher (rural or remote). More than 500 communities in Ontario are considered rural or remote, most populations ranging from a few hundred people to about 20000 . Major urban areas tend to have populations between 100000 and 2.5 million; some smaller centres near major cities also fall into this category.

We examined patient morbidity using prevalence data for acute myocardial infarction, congestive heart failure, diabetes mellitus and hypertension. ${ }^{11-14}$ We used the Johns Hopkins Adjusted Clinical Groups Case-Mix System ${ }^{15}$ to measure comorbidity and morbidity. The system uses diagnostic information obtained from administrative databases to describe and predict the use of health care resources. In this study, we used Resource Utilization Bands, which range from 0 (lowest expected health care costs) to 5 (highest expected health care costs), to categorize patients according to their morbidity and corresponding expected use of health care resources; we used Aggregated Diagnosis Groups, which range from 0 (no diagnosis group) to $\geq 10$ (at least 10 distinct diagnosis groups) to measure the level of comorbidity.

\section{Data sources}

We obtained data through a comprehensive research agreement with the Ontario Ministry of Health and Long-Term Care. The Corporate Provider Database, current to March 2007, was the source we used for demographic data on practising physicians in Ontario. For country of graduation we used the Institute for Clinical Evaluative Sciences Physician Database, current to the 2004 fiscal year.

To identify patients enrolled by study physicians, we used Client Agency Program Enrolment tables for the period Sept. 1, 2005, to Aug. 31, 2006. The Registered Persons Database, Ontario's health care registry, provided us with patient information (e.g., age, sex and place of residence) for all people covered by the Ontario Health Insurance Plan. We used physician billing claims submitted to the Ontario Health Insurance Plan to identify patient visits by type (physician's office, inpatient, emergency department or after-hours visit) and to identify diagnoses and provision of different types of services. We used the Canadian Institute for Health Information's Discharge Abstract Database to obtain data on hospital diagnoses and its National Ambulatory Care Registry System to obtain data on visits to emergency departments.

We derived neighbourhood income quintiles by linking 2001 census data to the patients' residential postal code data. Statistics Canada adjusted income for household size and community size such that each community would be expected to have $20 \%$ of its population in each income quintile.

\section{Outcome measures}

The Ontario Ministry of Health and Long-Term Care defines comprehensiveness of care according to a group of 21 different services. We calculated the mean number and percent of services provided by physicians in each model, stratified by geographic location. We examined continuity of care using the Usual Provider of Care and Continuity of Care indices. ${ }^{16-18}$ We used the fee code for after-hours visits to calculate the proportion of visits made after hours.

We examined the number of visits to emergency departments in each model, stratified by geographic location, to 
Table 1: Characteristics of enhanced fee-for-service and capitation models*

\begin{tabular}{|c|c|c|}
\hline Characteristic & Enhanced fee-for-service model & Capitation model \\
\hline Roster size & No limit & $\begin{array}{l}\text { No limit; base capitation rate is reduced by } 50 \% \\
\text { for each patient enrolled beyond an average of } \\
2400 \text { patients per physician }\end{array}$ \\
\hline Patient enrolment & Optional & Required \\
\hline After-hours call & Required & Required \\
\hline Fee-for-service payments & $\begin{array}{l}\text { Full payment plus } 10 \% \text { premium for } \\
21 \text { comprehensive care services }\end{array}$ & $\begin{array}{l}\text { Payment at } 10 \% \text { of full rate for } 56 \text { services for } \\
\text { enrolled patients; established maximum fee- } \\
\text { for-service payments annually }\end{array}$ \\
\hline Capitation rate & Not applicable & Adjusted for age and sex \\
\hline Access bonus & Not applicable & $\begin{array}{l}\text { Additional payment, reduced if enrolled } \\
\text { patient sees a nonspecialist physician outside } \\
\text { the group }\end{array}$ \\
\hline Extended hours & $\begin{array}{l}\text { One 3-hour evening or weekend session per } \\
\text { physician per week, to a maximum of } 5 \text { sessions; } \\
\text { exempted if }>50 \% \text { of physicians provide } \\
\text { emergency, anesthesia or obstetrics coverage }\end{array}$ & Same as enhanced fee-for-service model \\
\hline Income stabilization & Not applicable & Guaranteed annual income for new graduates \\
\hline $\begin{array}{l}\text { Management of } \\
\text { comprehensive care }\end{array}$ & $\begin{array}{l}\text { Monthly capitation payment of } \$ 2.15 \text { per } \\
\text { enrolled patient after the first year to } \\
\text { physicians who provide after-hours block } \\
\text { coverage }\end{array}$ & Same as enhanced fee-for-service model \\
\hline After-hours care & $\begin{array}{l}\text { Additional } 20 \% \text { of fee-for-service payment for } \\
\text { enrolled and virtually enrolled patients for } 9 \\
\text { basic office services }\end{array}$ & Same as enhanced fee-for-service model \\
\hline Diabetes care & $\begin{array}{l}\text { Annual fee per enrolled patient for } \\
\text { coordinating, providing and documenting } \\
\text { required elements of diabetes care }\end{array}$ & Same as enhanced fee-for-service model \\
\hline $\begin{array}{l}\text { Group management and } \\
\text { leadership }\end{array}$ & Not applicable & Annual fee per enrolled patient \\
\hline Targeted medical education & Not applicable & Hourly fee up to 24 hours \\
\hline Palliative care & $\begin{array}{l}\text { Annual fee after billing for palliative care for } \\
4 \text { or more enrolled patients }\end{array}$ & $\begin{array}{l}\text { Not applicable but eligible for full fee-for- } \\
\text { service payments for palliative care, obstetric } \\
\text { deliveries, hospital services, office procedures, } \\
\text { prenatal care, home visits (other than palliative) }\end{array}$ \\
\hline $\begin{array}{l}\text { Management of heart failure } \\
\text { care }\end{array}$ & $\begin{array}{l}\text { Annual fee per enrolled patient for } \\
\text { coordinating, providing and documenting } \\
\text { required elements of heart failure care }\end{array}$ & Same as enhanced fee-for-service model \\
\hline Smoking cessation & $\begin{array}{l}\text { Annual fee per enrolled patient who smokes to } \\
\text { initiate dialogue about quitting and to provide } \\
\text { dedicated subsequent counselling sessions }\end{array}$ & Same as enhanced fee-for-service model \\
\hline Cumulative preventive care & $\begin{array}{l}\text { Annual fee for reaching cumulative preventive } \\
\text { care thresholds (i.e., Papanicolaou smears, } \\
\text { mammograms, childhood immunizations, flu } \\
\text { shots, screening for colorectal cancer) }\end{array}$ & Same as enhanced fee-for-service model \\
\hline Serious mental illness & $\begin{array}{l}\text { Annual fee for } 5-9 \text { enrolled patients with } \\
\text { bipolar disorder or schizophrenia; fee doubles } \\
\text { for } 10 \text { or more patients }\end{array}$ & Same as enhanced fee-for-service model \\
\hline Unattached patient fee & $\begin{array}{l}\text { A one-time fee for enrolling an acute care } \\
\text { patient without a family physician following } \\
\text { discharge from an inpatient hospital stay }\end{array}$ & Same as enhanced fee-for-service model \\
\hline New patient premium & $\begin{array}{l}\text { A one-time fee for up to } 60 \text { enrolled new } \\
\text { patients without a family physician; increase in } \\
\text { fee for patients aged } 65-74 \text {, and further } \\
\text { increase in fee for patients aged } 75 \text { and over }\end{array}$ & Same as enhanced fee-for-service model \\
\hline New graduate incentive & $\begin{array}{l}\text { Fee for enrolling up to } 300 \text { people who qualify } \\
\text { as new patients in the first year of practice }\end{array}$ & Same as enhanced fee-for-service model \\
\hline
\end{tabular}


determine whether enhanced access to care resulted in fewer visits to emergency departments. We evaluated semiurgent and nonurgent visits to emergency departments (Canadian Triage and Acuity Scale categories 4 and 5) in relation to more urgent visits (categories 1 to 3 ).${ }^{19}$ We compared the number of visits made by enrolled patients during the study period with the number of visits made by the same patients from Sept. 1, 2003, to Aug. 31, 2004; we chose this earlier period for comparison because it was before most of the study physicians had joined a capitation or enhanced fee-for-service group. We limited our analysis to patients who were alive on Sept. 1, 2003.

We examined the number of patients without a physician (unattached patients) enrolled by study physicians in each model during the study period. We also examined the number of unattached patients enrolled by new graduates in each model.

\section{Statistical analysis}

We used regression models to control for physician and patient characteristics for the main outcomes of after-hours visits and visits to emergency departments. We adjusted for the physician characteristics of practice size, foreign graduation, years since graduation, months in practice group and group size. We also adjusted for patient characteristics, including age, sex, neighbourhood income quintile, morbidity, comorbidity and time enrolled in the physician group. We built Poisson regression models, which used generalized estimating equations, to account for the lack of independence resulting from the nested structure of the data (patients nested within physician nested within group).

\section{Research ethics approval}

This study was approved by the Research Ethics Board of Sunnybrook Health Sciences Centre, Toronto, Ontario.

\section{Results}

Physician characteristics were similar across the capitation and enhanced fee-for-service groups except for a lower proportion of foreign graduates in the capitation model (Table 2). Compared with physicians in the enhanced fee-for-service model, those in the capitation model had more enrolled patients; they also had a higher proportion of inpatient and emergency department visits relative to office visits. These patterns were consistent across geographic areas. In both the capitation and enhanced fee-for-service models, physicians in rural areas were more likely than those in urban areas to be male and less likely to be foreign graduates. In addition, rural physicians had fewer enrolled patients and had a higher proportion of inpatient and emergency department visits relative to office visits compared with physicians in urban areas.

The age, sex and socioeconomic characteristics of patients were similar across the capitation and enhanced fee-forservice groups (Table 3). Those whose physicians were in the capitation group were less likely to have chronic conditions and had less morbidity and comorbidity compared with patients whose physicians were in the enhanced fee-for-service group. The lowest income quintile, expected to comprise $20 \%$ of the population, was underrepresented in both models except for capitation practices in rural areas, where it was overrepresented. Patients in rural areas were more likely to have chronic conditions but did not differ substantially in overall morbidity

Table 2: Characteristics of study physicians* in enhanced fee-for-service and capitation groups, by location

\begin{tabular}{|c|c|c|c|c|c|c|c|c|}
\hline \multirow[b]{2}{*}{ Characteristic } & \multicolumn{2}{|c|}{ All locations } & \multicolumn{2}{|c|}{ Major urban centres } & \multicolumn{2}{|c|}{ Non-major urban centres } & \multicolumn{2}{|c|}{ Rural centres } \\
\hline & $\begin{array}{l}\text { Enhanced } \\
\text { fee-for-service }\end{array}$ & Capitation & $\begin{array}{l}\text { Enhanced } \\
\text { fee-for-service }\end{array}$ & Capitation & $\begin{array}{c}\text { Enhanced } \\
\text { fee-for-service }\end{array}$ & Capitation & $\begin{array}{l}\text { Enhanced } \\
\text { fee-for-service }\end{array}$ & Capitation \\
\hline No. of physicians & 3553 & 507 & 2646 & 233 & 734 & 177 & 173 & 97 \\
\hline No. of groups & 274 & 53 & 179 & 21 & 73 & 21 & 22 & 11 \\
\hline Male, no. (\%) & $2267(63.8)$ & $319(62.9)$ & $1657(62.6)$ & $130(55.8)$ & $490(66.8)$ & $121(68.4)$ & $120(69.4)$ & $68(70.1)$ \\
\hline Age, yr, mean (SD) & $49.4 \quad(9.9)$ & $47.5 \quad(9.3)$ & $49.7 \quad(9.9)$ & $47.9(9.1)$ & $48.4(10.0)$ & $47.2(9.6)$ & $48.8(10.4)$ & $47.1 \quad(9.4)$ \\
\hline $\begin{array}{l}\text { No. of years since } \\
\text { graduation, mean (SD) }\end{array}$ & $23.9(10.3)$ & $21.8 \quad(9.8)$ & $24.4(10.2)$ & $22.4(9.6)$ & $22.7(10.5)$ & $21.5 \quad(9.7)$ & $22.6(10.8)$ & $21.1(10.4)$ \\
\hline $\begin{array}{l}\text { Foreign graduate, } \\
\text { no. }(\%)\end{array}$ & $682(19.2)$ & $47 \quad(9.3)$ & $558(21.1)$ & $29(12.4)$ & $96(13.1)$ & $12(6.8)$ & $28(16.2)$ & $6 \quad(6.2)$ \\
\hline $\begin{array}{l}\text { Total no. patients } \\
\text { enrolled, mean (SD) }\end{array}$ & $708.6(566.9)$ & $960.8(617.7)$ & 716.5 (559.7) & $1007.6(705.3)$ & $707.6(594.5)$ & $989.7(583.6)$ & $591.4(560.5)$ & 795.7 (469.5) \\
\hline $\begin{array}{l}\text { No. of months in } \\
\text { group, median (IQR) }\end{array}$ & $25.3(16.5)$ & $25.7(14.0)$ & $24.4(17.3)$ & $25.3(15.0)$ & $28.8(14.9)$ & $25.0(16.0)$ & $24.4(11.1)$ & $28.0 \quad(8.0)$ \\
\hline \multicolumn{9}{|l|}{ Type of visits, \% } \\
\hline Office & 86 & 76 & 90 & 85 & 79 & 74 & 66 & 57 \\
\hline Inpatient & 4 & 8 & 3 & 5 & 7 & 10 & 10 & 13 \\
\hline $\begin{array}{l}\text { Emergency } \\
\text { department }\end{array}$ & 3 & 7 & 1 & 1 & 7 & 8 & 14 & 20 \\
\hline Other & 7 & 9 & 7 & 9 & 8 & 8 & 10 & 10 \\
\hline
\end{tabular}

Note: IQR = interquartile range, SD = standard deviation.

*Physicians who were consistently part of the same enhanced fee-for-service or capitation group from Sept. 1, 2005, to Aug. $31,2006$. 
or comorbidity with patients in other geographic areas.

Comprehensiveness of care was slightly higher in the enhanced fee-for-service practices than in the capitation practices. Continuity of care was similar across the groups (Table 4). The proportion of visits billed as after-hours visits was lower in the capitation group than in the enhanced fee-forservice group; the same was true for the proportion of afterhours visits that were to study physicians. The proportion of physicians with no after-hours visits was higher in the capitation than in the enhanced fee-for-service group. Comprehensiveness of care was similar across locations; however, continuity of care was higher in rural areas than in urban areas in both the capitation and enhanced fee-for-service groups. Patients in rural areas had considerably less after-hours care than patients in urban areas; however, the proportion of afterhours visits that were to enrolling physicians was higher in rural areas.

Patterns of use of emergency department services are indi- cated in Table 5. Compared with patients in enhanced fee-forservice practices, those in capitation practices had more visits to emergency departments, a higher proportion of visits that were semiurgent and nonurgent, and a lower proportion of visits to emergency departments that were after hours. Patients in non-major urban centres and rural areas had higher rates of emergency department use and a higher proportion of visits that were less urgent than patients in urban areas. Use of emergency department services by the study patients in 2003/04 was similar to use during the study period (Table 5).

After adjustment for physician and patient characteristics, we found that patients in capitation practices continued to have less after-hours care than patients in enhanced fee-forservice practices. This trend was consistent across geographic locations; the difference was strongest in rural areas and not significant in non-major urban areas (Figure 1). The difference in after-hours visits overall by geographic location continued after we adjusted for physician and patient characteris-

Table 3: Characteristics of study patients* in enhanced fee-for-service and capitation practices, by location

\begin{tabular}{|c|c|c|c|c|c|c|c|c|}
\hline \multirow[b]{3}{*}{ Characteristic } & \multicolumn{8}{|c|}{ Location / physician group; no. (\%) of patients } \\
\hline & \multicolumn{2}{|c|}{ All locations } & \multicolumn{2}{|c|}{ Major urban centres } & \multicolumn{2}{|c|}{ Non-major urban centres } & \multicolumn{2}{|c|}{ Rural centres } \\
\hline & $\begin{array}{c}\text { Enhanced } \\
\text { fee-for-service }\end{array}$ & Capitation & $\begin{array}{c}\text { Enhanced } \\
\text { fee-for-service }\end{array}$ & Capitation & $\begin{array}{c}\text { Enhanced } \\
\text { fee-for-service }\end{array}$ & Capitation & $\begin{array}{l}\text { Enhanced } \\
\text { fee-for-service }\end{array}$ & Capitation \\
\hline No. of patients & 2517527 & 487131 & 1895801 & 234773 & 519412 & 175177 & 102314 & 77181 \\
\hline $\begin{array}{l}\text { Age as of January } \\
2006, y r \text {, mean (SD) }\end{array}$ & $41.2(23.0)$ & $40.5(23.0)$ & $40.8(22.8)$ & $39.9(22.5)$ & $41.6(23.8)$ & $40.2(23.4)$ & $42.9(23.5)$ & $43.1(23.8)$ \\
\hline \multicolumn{9}{|l|}{ Age group, yr } \\
\hline$<2$ & $45434 \quad(1.8)$ & 7254 (1.5) & 34396 (1.8) & 3432 (1.5) & $9535 \quad(1.8)$ & 2847 (1.6) & 1503 & $975(1.3)$ \\
\hline $2-64$ & $2027088(80.5)$ & $397083(81.5)$ & $1538769(81.2)$ & $195708(83.4)$ & $408527(78.7)$ & $141942(81.0)$ & $79792(78.0)$ & $59433(77.0)$ \\
\hline$\geq 65$ & $445005(17.7)$ & $82794(17.0)$ & $322636(17.0)$ & $35633(15.2)$ & $101350(19.5)$ & $30388(17.3)$ & $21019(20.5)$ & $16773(21.7)$ \\
\hline Male & $1111376(44.1)$ & 225652 (46.3) & $834125(44.0)$ & 106264 (45.3) & $230875(44.4)$ & $82926(47.3)$ & $46376(45.3)$ & 36462 (47.2) \\
\hline \multicolumn{9}{|l|}{$\begin{array}{l}\text { Neighbourhood } \\
\text { Income quintile }\end{array}$} \\
\hline 1 (lowest) & 364470 (14.5) & 76120 (15.6) & $273693(14.4)$ & $32343(13.8)$ & $73824(14.2)$ & $23095(13.2)$ & $16953(16.6)$ & $20682(26.8)$ \\
\hline 2 & 443833 (17.6) & 91881 (18.9) & 328811 (17.3) & 38881 (16.6) & 96555 (18.6) & 30797 (17.6) & $18467(18.0)$ & 22203 (28.8) \\
\hline 3 & $509274(20.2)$ & 94948 (19.5) & 377752 (19.9) & 46092 (19.6) & $110165(21.2)$ & $36393(20.8)$ & 21357 (20.9) & 12463 (16.1) \\
\hline 4 & $564544(22.4)$ & $100329(20.6)$ & $427634(22.6)$ & $53385(22.7)$ & $114600(22.1)$ & $39490(22.5)$ & $22310(21.8)$ & 7454 (9.7) \\
\hline 5 (highest) & $582441(23.1)$ & $105068(21.6)$ & $449654(23.7)$ & $60031(25.6)$ & 113797 (21.9) & $39503(22.6)$ & $18990(18.6)$ & $5534 \quad(7.2)$ \\
\hline Missing data & $52965 \quad(2.1)$ & $18785 \quad(3.9)$ & $38257 \quad(2.0)$ & $4041 \quad(1.7)$ & $10471 \quad(2.0)$ & $5899 \quad(3.4)$ & 4237 & 8845 (11.5) \\
\hline $\begin{array}{l}\text { Previous acute } \\
\text { myocardial infarction }\end{array}$ & $36577 \quad(1.5)$ & 6948 (1.4) & $25592 \quad(1.3)$ & 2941 (1.3) & $8895 \quad(1.7)$ & $2604 \quad(1.5)$ & $2090 \quad(2.0)$ & 1403 (1.8) \\
\hline $\begin{array}{l}\text { Congestive heart } \\
\text { failure }\end{array}$ & $57213 \quad(2.3)$ & $10229(2.1)$ & $39324 \quad(2.1)$ & $4023 \quad(1.7)$ & $14458(2.8)$ & 3966 (2.3) & 3431 (3.4) & $2240 \quad(2.9)$ \\
\hline Diabetes mellitus & $227718 \quad(9.0)$ & $34173 \quad(7.0)$ & 171228 (9.0) & $15949 \quad(6.8)$ & $46566 \quad(9.0)$ & $11932 \quad(6.8)$ & $9924 \quad(9.7)$ & 6292 (8.2) \\
\hline Hypertension & $635629(25.2)$ & $104650(21.5)$ & $468400(24.7)$ & 47949 (20.4) & $138621(26.7)$ & $38563(22.0)$ & $28608(28.0)$ & 18138 (23.5) \\
\hline $\begin{array}{l}\text { Resource Utilization } \\
\text { Band, } \neq \text { mean (SD) }\end{array}$ & $2.4(1.1)$ & $2.1(1.2)$ & $2.5(1.1)$ & $2.2(1.2)$ & $2.4(1.2)$ & $2.1(1.2)$ & $2.4(1.2)$ & $2.1(1.3)$ \\
\hline \multicolumn{9}{|l|}{$\begin{array}{l}\text { No. of Aggregated } \\
\text { Diagnosis Groups§ }\end{array}$} \\
\hline$<5$ & 79.3 & 88.0 & 78.6 & 87.6 & 81.3 & 87.9 & 82.5 & 89.0 \\
\hline $6-9$ & 17.9 & 10.7 & 18.5 & 11.0 & 16.1 & 10.7 & 15.1 & 9.8 \\
\hline$\geq 10$ & 2.8 & 1.3 & 2.9 & 1.4 & 2.5 & 1.4 & 2.4 & 1.3 \\
\hline
\end{tabular}

Note: SD = standard deviation.

*Patients enrolled to a physician who was consistently part of the same enhanced fee-for-service or capitation group from Sept. 1, 2005 , to Aug. 31, 2006. tUnless stated otherwise.

¥Resource Utilization Bands categorize patients according to their morbidity and corresponding expected use of health care resources; they range from 0 (lowest expected health care costs) to 5 (highest expected health care costs).

§Aggregated Diagnosis Groups indicate a patients level of comorbidity, ranging from 0 (no diagnosis group) to $\geq 10$ (at least 10 distinct diagnosis groups). 
tics, with many fewer after-hours visits in rural areas than in major urban and non-major urban areas. Physician characteristics associated with increased after-hours visits included higher patient enrolment, male sex, foreign graduation, fewer years since graduation and smaller group size. Patient characteristics associated with increased after-hours visits included low neighbourhood income quintile, decreasing age, female sex, and higher morbidity and comorbidity indices.

After adjustment for physician and patient characteristics, we found that patients in capitation practices continued to have higher rates of use of emergency department services than patients in enhanced fee-for-service practices. This finding was consistent and significant across all 3 geographic locations (Figure 2). Patients in non-major urban and rural areas had more visits to an emergency department than patients in urban areas. Physician factors associated with increased emergency department visits included fewer enrolled patients, male sex, longer time belonging to a group, graduation from a Canadian medical school and small group size. Patient factors associated with increased emergency department visits included low neighbourhood income quintile, decreas- ing age, male sex, and higher morbidity and comorbidity.

Overall, physicians in capitation practices enrolled fewer new patients (37.0 per physician) than did physicians in enhanced fee-for-service practices (52.0 per physician). The same was true of new graduates, with 60.3 new patients enrolled per physician in capitation practices and 72.1 per physician in enhanced fee-for-service practices.

\section{Interpretation}

We analyzed data collected during one of the largest modern conversions from a fee-for-service to a capitation-based physician reimbursement model. We found several distinct differences in practice characteristics between these models. Compared with practices in the enhanced fee-for-service model, those in the capitation model had patients who had lower morbidity and comorbidity indices, received less after-hours care and had more visits to emergency departments. In addition, they had physicians who enrolled fewer new patients. Both models had patients of higher socioeconomic status than expected in their community. Compared with patients in

Table 4: Comprehensiveness of care provided in enhanced fee-for-service and capitation groups, by location

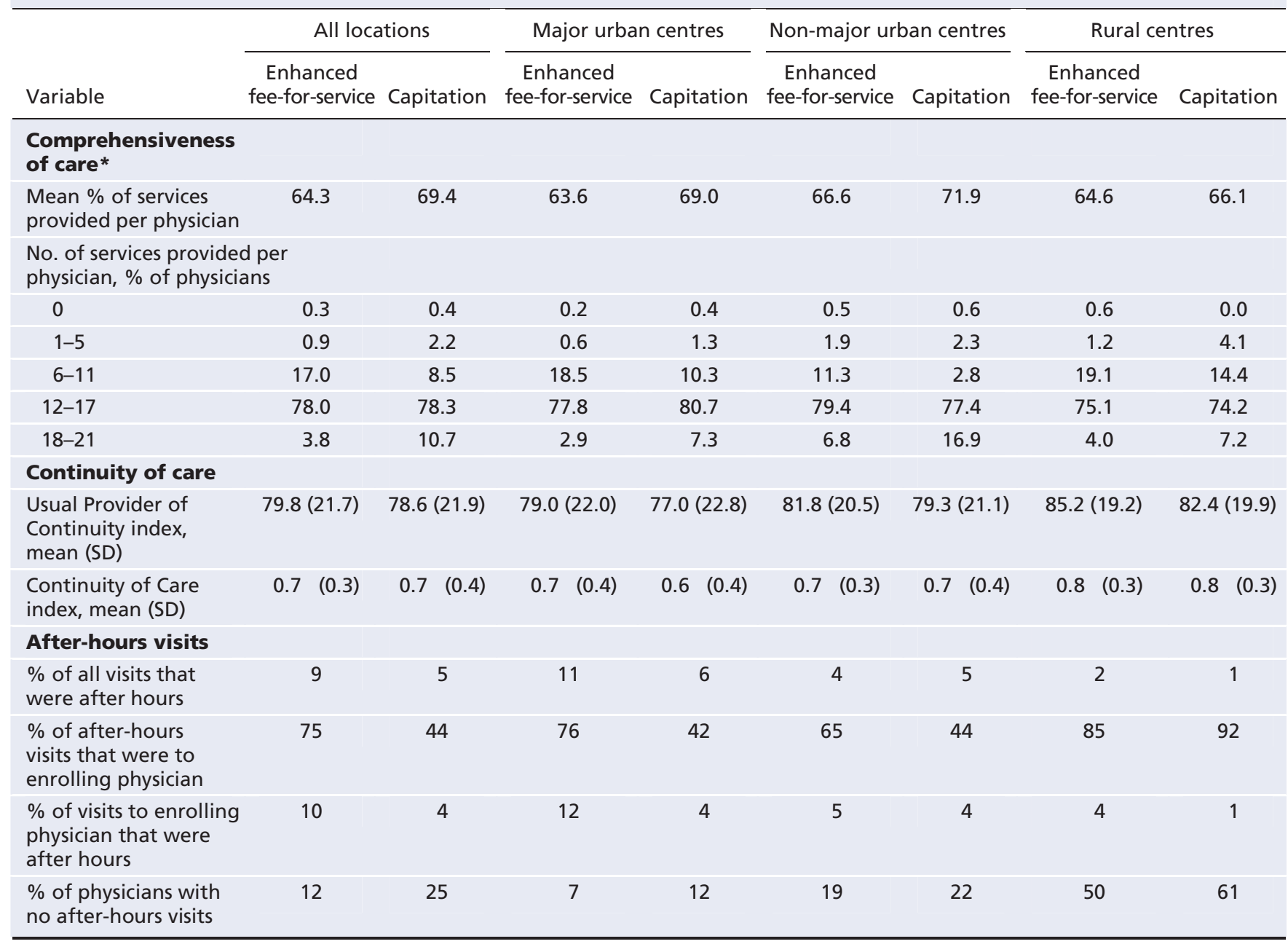

Note: $\mathrm{SD}=$ standard deviation.

*Calculated as the mean number and percent of 21 services provided by physicians in each model. Ontario Health Insurance Plan billing codes for the 21 services are as follows: A001, A003, A007, A008, A888, A901, A902, C010, C882, E075, G365, G538, G539, G590, G591, K005, K013, K017, K022, K023 and K030. 
enhanced fee-for-service practices, those in capitation practices had higher rates of use of emergency department services both during the study period and during the period before their physicians were likely to have changed reimbursement models. This finding suggests that this was a pre-existing pattern of use and not a result of the conversion to the capitation model. The capitation model appears to have attracted physicians with certain practice styles and patient populations.

The capitation model that we examined was not set up to adjust for patient morbidity and comorbidity. Therefore, payment was adjusted only for age and sex, which may have contributed to the differences in morbidity and comorbidity that we observed between the 2 practice types. Another feature of the capitation model is large retention bonuses when patients do not seek outside primary care. This feature probably contributed to the higher proportion of physicians in rural areas choosing the capitation model than the enhanced fee-forservice model because there is less availability of outside care in smaller centres than in urban centres. Exemptions from evening and weekend clinics for groups providing hospitalbased services probably contributed to reduced after-hours care and possibly higher rates of emergency department visits.

At the time the blended capitation model was introduced, selection of primary care residency positions by medical students was at an all-time low, ${ }^{20}$ reimbursement of primary care physicians was a fraction of that paid to specialists, ${ }^{21}$ satisfaction with professional life was low, ${ }^{22}$ and the number of underserviced communities had almost doubled. ${ }^{23}$ Many of these situations have improved since then, perhaps in part due to primary care reform. From that perspective, increased reimbursement to primary care physicians, even without attending changes in practice, may have been an appropriate policy direction. Also, payers have more predictable costs under a capitation model than under a fee-for-service model. As well, team-based care may be easier to implement when physicians are not dependent on fee- for-service payments. In fact, a new team-based model of care based in large part on the capitation model was just being implemented during the period of our study.

There is little evidence available from other countries on changes in access to care under capitation models. A systematic review revealed inconsistent evidence about changes in access to care and health care utilization between capitation and fee-for-service models. ${ }^{6}$ A comparative Canadian study in the 1990s found no change in the use of hospital services between blended capitation and matched fee-for-service practices. ${ }^{24}$ More recent studies in the United States that compared capitation and fee-for-service models reported conflicting findings about the provision of discretionary care,$^{25}$ rates of "ambulatory care sensitive" hospital admissions (admissions that could have been avoided through timely ambulatory

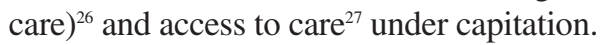

An analysis of the strengths and weaknesses of the models suggests that no single model can achieve the full range of policy objectives. ${ }^{28}$ Information that would guide policymakers about the blending of different elements with capitation, adjustment of capitation rates, incentives and disincentives for care outside the model, and other model elements to achieve improved access is extremely limited.

A recent study found that rates of use of emergency department services were lower in capitation practices than in enhanced fee-for-service practices. However, the findings were based on self-report and examined a small number of groups in only one city. ${ }^{29}$ Our findings were based on actual use of emergency department services and included data for the entire province of Ontario. Both administrative data ${ }^{30}$ and physician surveys $^{31}$ have shown that, on average, primary care physicians in rural areas provide more emergency care and hospital-based care than do physicians in urban areas. These studies also showed a greater scope of practice in rural areas, a finding not reflected in our mostly office-based measure of comprehen-

Table 5: Use of emergency department services by study patients, by location and type of physician group

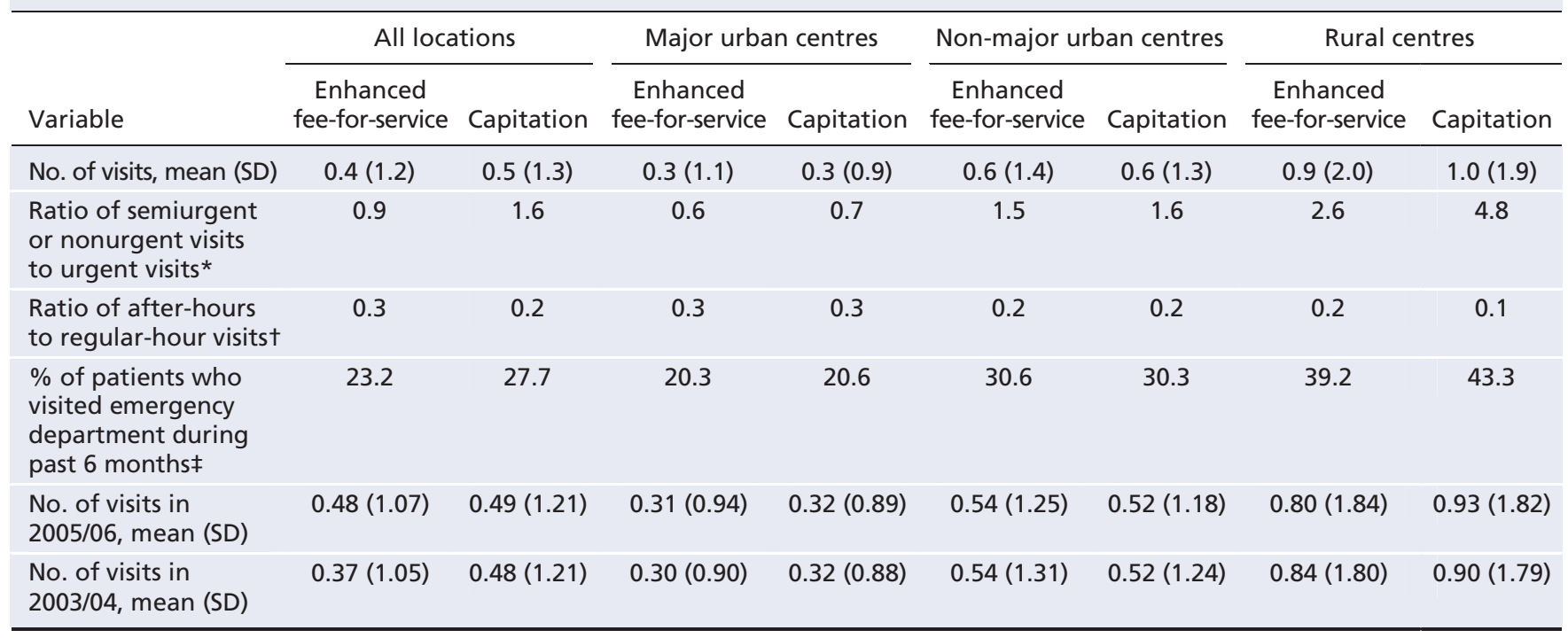

Note: $\mathrm{SD}=$ standard deviation.

*Semiurgent and nonurgent visits were those rated as 4 and 5 on the Canadian Triage and Acuity Scale; urgent visits were those rated as 1,2 or 3 on the scale. ${ }^{19}$

tVisits during regular hours were those on weekdays from 9 am to $5 \mathrm{pm}$.

†From October 2005 to March 2006. 
siveness of care. In our study we found the mean number of visits to emergency departments was much higher in rural areas than in urban areas, a finding also documented by others. ${ }^{32,33}$

\section{Limitations}

Our study had limitations. First, and largest, was the dependence on administrative data. However, because we collected billing data based on fee codes that are used to pay physicians, we feel that the data were reasonably complete. Physicians in the capitation model, however, bill fee-for-service but are paid only $10 \%$ on claims; it is not yet known whether capitation claims are as complete as fee-for-service claims. Incomplete billing claims for afterhours care by physicians in capitation practices would
Variable

Physician characteristics

Capitation (v. enhanced fee-for-service)

Location (v. major urban)

Non-major urban

Rural

No. of patients enrolled (v. $\geq 650)$

$1-100$

$101-649$

Male (v. female)

No. of months in group (v. $>35)$

$\leq 19$

20-28

29-35

Graduate of Canadian medical school

(v. foreign trained)

No. of years since graduation (v. $>31$ )

$$
\leq 17
$$

$18-25$

26-31

No. of physicians in group (v. 3-9)

$10-24$

25-49

$50-99$

$\geq 100$

Patient characteristics

Income quintile (v. first [lowest])

Second

Third

Fourth

Fifth (highest)

Missing data

Age, yr (v. 2-64)

$<2$

$\geq 65$

Male (v. female)

No. of Resource Utilization Bands* (v. 0-1)

2

3

$\geq 4$

No. of Aggregated Diagnosis Groupst (v. $<5)$

6-9

$\geq 10$
Adjusted OR $(95 \% \mathrm{Cl})$

$\begin{array}{ll}0.68 & (0.61-0.75) \\ 0.64 & (0.59-0.70) \\ 0.19 & (0.14-0.25) \\ & \\ 0.88 & (0.73-1.04) \\ 0.84 & (0.78-0.90) \\ 1.20 & (1.12-1.29) \\ & \\ 1.04 & (0.95-1.15) \\ 0.91 & (0.83-0.99) \\ 1.01 & (0.92-1.10) \\ 0.81 & (0.74-0.88)\end{array}$

1.22

1.03

$(1.10-1.34)$

$(0.94-1.13)$

1.15

$(1.05-1.27)$

$0.68 \quad(0.62-0.74)$

$0.66 \quad(0.60-0.72)$

$0.75 \quad(0.66-0.85)$

$0.93 \quad(0.83-1.04)$

$1.04 \quad(1.02-1.07)$

$1.03 \quad(1.00-1.06)$

$1.01 \quad(0.98-1.05)$

$0.87 \quad(0.84-0.91)$

$0.93 \quad(0.89-0.97)$

$1.64 \quad(1.59-1.69)$

$0.43 \quad(0.42-0.45)$

$0.95 \quad(0.94-0.96)$

$3.20 \quad(3.14-3.26)$

$4.46 \quad(4.35-4.56)$

$3.54 \quad(3.44-3.64)$

$1.92(1.90-1.95)$

$2.98(2.89-3.07)$
Decreased likelihood of Increased likelihood of $\longleftarrow$ after-hour visits after-hour visits $\longrightarrow$

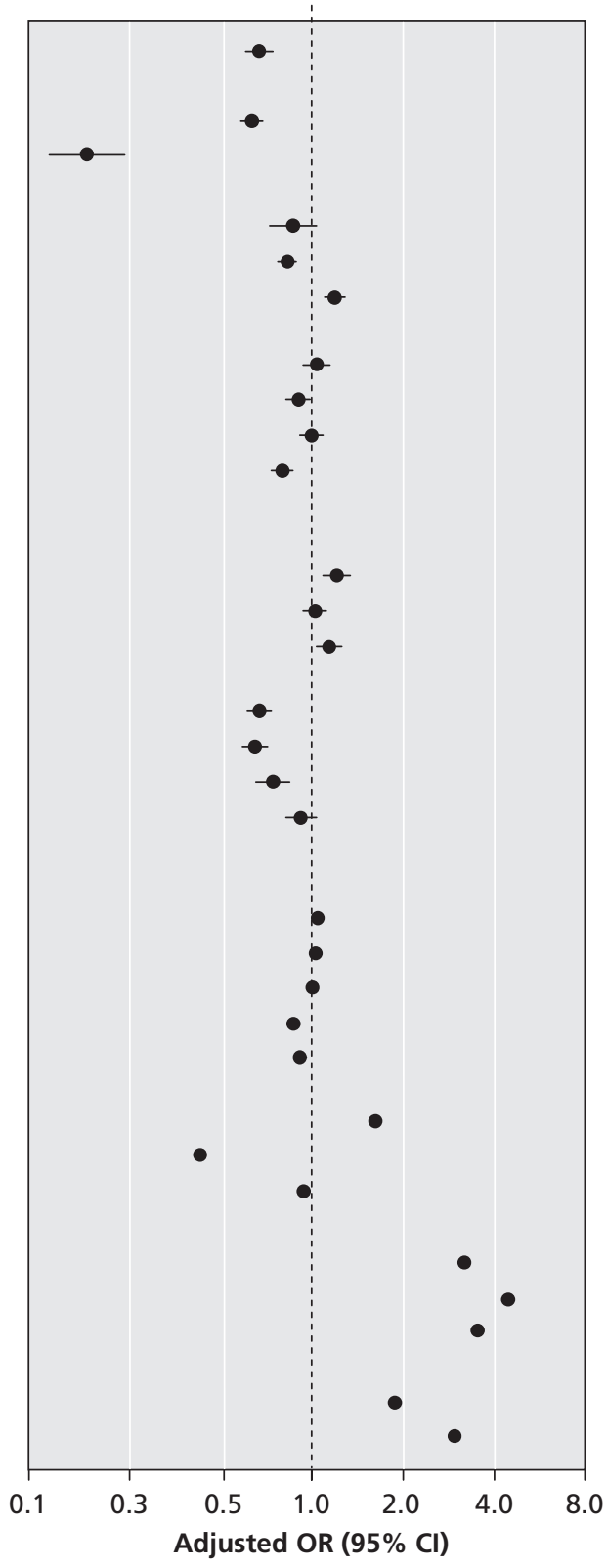

Figure 1: Adjusted odds ratios (ORs) of after-hours visits among patients whose physicians were reimbursed through a blended capitation model compared with patients whose physicians were reimbursed through an enhanced fee-for-service model. Adjustments were made for the physician and patient characteristics listed in the figure. Values less than 1.0 indicate fewer after-hours visits in the capitation model than in the enhanced fee-for-service model. $\mathrm{Cl}=$ confidence interval. *Resource Utilization Bands categorize patients according to their morbidity and corresponding expected use of health care resources; they range from 0 (lowest expected health care costs) to 5 (highest expected health care costs). †Aggregated Diagnosis Groups indicate a patient's level of comorbidity, ranging from 0 (no diagnosis group) to $\geq 10$ (at least 10 distinct diagnosis groups). 
appear as reduced provision of after-hours care in our data.

Second, patient enrolment is required under the capitation model but is optional under the enhanced fee-for-service model. If a smaller proportion of patients were enrolled in enhanced fee-for-service practices than in capitation practices, and if patients with frequent visits were more likely to be enrolled, the result may have been sicker patients enrolled in the enhanced fee-for-service practices than in the capitation practices.
Third, we limited patients to those enrolled for the entire study year. However, patients continued to be enrolled during that period. Further research involving these practices over an extended study period would be warranted. Ontario has 43 urban and 11 rural community health centres that serve highneed populations but for which data are not available; this potentially contributed to the skewing of socioeconomic status in the practices included in our study.

Variable
Physician characteristics
Capitation (v. enhanced fee-for-service)
Location (v. major urban)
Non-major urban
Rural
No. of patients enrolled $(v . \geq 650)$
1-100
101-649
Male (v. female)
No. of months in group (v. $>35)$
$\leq 19$
$20-28$
$29-35$

Graduate of Canadian medical school (v. foreign trained)

No. of years since graduation (v. > 31) $\leq 17$

$18-25$

26-31

No. of physicians in group (v. 3-9)

10-24

25-49

50-99

$\geq 100$

Patient characteristics

Income quintile (v. first [lowest])

Second

Third

Fourth

Fifth (highest)

Missing data

Age, yr (v. 2-64)

$<2$

$\geq 65$

Male (v. female)

Resource Utilization Band* (v. 0-1)

2

3

$\geq 4$

Aggrego

Adjusted OR $(95 \% \mathrm{Cl})$

$1.20(1.15-1.25)$

$1.70(1.64-1.75)$

$2.61(2.46-2.76)$

$1.13(1.05-1.21)$

$1.09(1.06-1.13)$

$1.10(1.07-1.14)$

$0.95(0.92-0.99)$

$0.98(0.94-1.02)$

$1.00(0.96-1.04)$

1.09 (1.05-1.13)

$0.97(0.93-1.01)$

0.99 (0.95-1.03)

$0.99(0.95-1.04)$

0.99 (0.95-1.02)

$0.96(0.92-0.99)$

$0.95(0.91-0.99)$

$0.79(0.76-0.82)$

$0.87(0.86-1.14)$

$0.80(0.79-0.81)$

$0.75(0.74-0.76)$

$0.69(0.68-0.71)$

$0.88(0.85-0.91)$

$1.77(1.77-1.82)$

$0.80(0.79-0.81)$

$1.15(1.14-1.15)$

$1.76(1.74-1.78)$

$2.36(2.33-2.39)$

$3.40(3.35-3.45)$

6-9

$\geq 10$

2.07 (2.05-2.09)

4.25 (4.18-4.32)

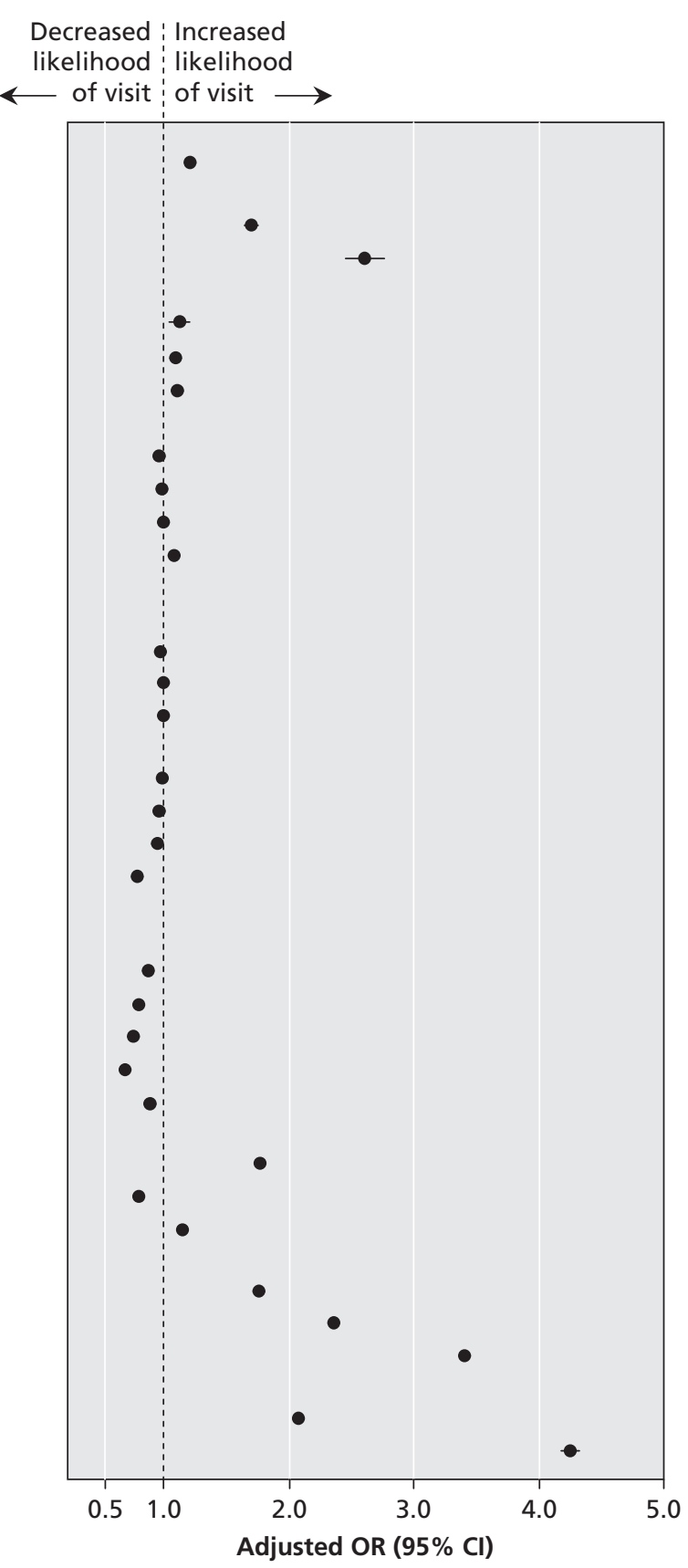

Figure 2: Adjusted odds ratios (ORs) of use of emergency department visits among patients whose physicians were reimbursed through a blended capitation model compared with patients whose physicians were reimbursed through an enhanced fee-for-service model. Adjustments were made for the physician and patient characteristics listed in the figure. Values greater than 1.0 indicate more visits to an emergency department in the capitation model than in the enhanced fee-for service model. $\mathrm{Cl}=$ confidence interval. *See caption of Figure 1 for explanations of Resource Utilization Bands and Aggregated Diagnosis Groups. 
Fourth, we did not compare the capitation and enhanced fee-for-service models with the other models of primary care reform in Ontario or with the straight fee-for-service plan. Data for the other models are either incomplete in Ontario or relate to models undergoing rapid change. Also, many primary care physicians who remain in the straight fee-forservice pool have practices that focus on specific aspects of care (e.g., sports medicine, palliative care or care of elderly people) such that they are not comparable with practices providing comprehensive care in patient enrolment models.

\section{Conclusion}

The capitation and enhanced fee-for-service models were comparable in terms of physician and patient characteristics. Both models were skewed toward patients with higher incomes. They were also comparable in terms of comprehensiveness and continuity of care. However, compared with the enhanced fee-for-service practices, the capitation practices had fewer sick patients, provided less after-hours care, had higher rates of use of emergency department services and enrolled fewer new patients. The differences in the practice characteristics between the 2 models appeared to be pre-existing rather than due to the conversion to the new capitation reimbursement model. Although the capitation model provides an alternative to fee-for-service practice, its characteristics should be the focus of future policy development and research.

This article has been peer reviewed.

Competing interests: None declared.

Contributors: All of the authors were involved in the conception and design of the study. Alexander Kopp was primjarily responsible for the data analysis, with additional contributions from Julie Klein-Geltink and Lyn Sibley. Richard Glazier and Julie Klein-Geltink prepared the first draft of the article, and Richard Glazier was responsible for subsequent revisions. All of the authors critically reviewed the article and approved the final version.

Acknowledgement: Lyn Sibley was supported by a Canadian Institute of Health Research-Institute for Health Services and Policy Research (CIHRIHSPR) postdoctoral fellowship.

Funding: This work was supported by the Canadian Institutes of Health Research (grant no. MOP 85013). This study was also supported by the Ontario Ministry of Health and Long-Term Care. The results and conclusions are those of the authors; no official endorsement by the Ontario Ministry of Health and Long-Term Care is intended or should be inferred.

\section{REFERENCES}

1. Bodenheimer T. Primary care - Will it survive? N Engl J Med 2006;355:861-4.

2. Health Analysis and Measurement Group. Access to health care services in Canada, 2003. Ottawa (ON): Statistics Canada; 2003. Cat. no. 82-575-XIE. Available: www.statcan.gc.ca/pub/82-575-x/82-575-x2003001-eng.pdf (accessed 2009 Apr. 28).

3. Tepper JD, Schultz SE, Rothwell DM, et al. Physician services in rural and Northern Ontario. ICES investigative report. Toronto (ON): Institute for Clinical Evaluative Sciences; 2005. Available: www.ices.on.ca/file/Physician_Services_in_Rural _and_Northern_Ontario.pdf (accessed 2009 Feb. 23).

4. Joint principles of the patient-centered medical home. American Academy of Family Physicians, American Academy of Pediatrics, American College of Physicians, American Osteopathic Association; 2007. Available: www.medicalhomeinfo.org /Joint\%20Statement.pdf (accessed 2009 Feb. 23).

5. National Health Service. Quality and outcomes framework 2007/2008. London (UK): The Service; 2008. Available: www.qof.ic.nhs.uk/ (accessed 2009 Feb. 23).

6. Gosden T, Forland F, Kristiansen IS, et al. Impact of payment method on behaviour of primary care physicians: a systematic review. J Health Serv Res Policy 2001;6:44-55.

7. Portrait of the Canadian population in 2006. Ottawa (ON): Statistics Canada; 2006. Available: www12.statcan.ca/english/census06/analysis/popdwell/ProvTerr4 .cfm (accessed 2009 Feb. 23).

8. Canada Health Act, R.S.C. 1985, c. C-6. Available: http://laws.justice.gc.ca/en/C-6 /?noCookie (accessed 200 Feb. 23).

9. Canadian Institute for Health Information. Supply, distribution and migration of Canadian physicians, 2006. Ottawa (ON): The Institute; 2007. Available: http://secure.cihi.ca/cihiweb/products/SupDistandMigCanPhysic_2006_e.pdf (accessed 2009 Feb. 23).

10. Kralj B. Measuring "rurality" for purposes of health-care planning: an empirical measure for Ontario. Toronto (ON): Ontario Medical Association; 2005. Available: www.oma.org/Shortage/Data/00rurality.asp (accessed 2009 Feb. 23).

11. Jackevicius CA, Li P, Tu JV. Prevalence, predictors, and outcomes of primary nonadherence after acute myocardial infarction. Circulation 2008;117:1028-36.

12. Ko DT, Alter DA, Austin PC, et al. Life expectancy after an index hospitalization for patients with heart failure: a population-based study. Am Heart J 2008;155:324-31.

13. Hux JE, Ivis F, Flintoft V, et al. Diabetes in Ontario: determination of prevalence and incidence using a validated administrative data algorithm. Diabetes Care 2002;25:512-6.

14. Tu K, Campbell NR, Chen Z, et al. Accuracy of administrative databases in identifying patients with hypertension. Open Med 2007;1:e5-7.

15. The Johns Hopkins University ACG Case-Mix Adjustment System [computer program]. Baltimore (MD): Johns Hopkins University School of Hygiene and Public Health; 1997.

16. Shortell SM. Continuity of medical care: conceptualization and measurement. Med Care 1976;14:377-91.

17. Breslau N, Reeb KG. Continuity of care in a university-based practice. J Med Educ 1975;50:965-9.

18. Bice TW, Boxerman SB. A quantitative measure of continuity of care. Med Care 1977; $15: 347-9$.

19. Beveridge R, Clarke B, Janes L. Canadian Emergency Department Triage and Acuity Scale. Implementation guidelines. CJEM 1999;1(3 Suppl):S2-28.

20. History of family medicine as the career choice of Canadian graduates [Table IX] In: Operations: reports and statistics. $R-1$ match reports -2003 . Ottawa (ON): Canadian Resident Matching Service; 2003. Table Available: www.carms.ca/eng /operations_R1reports_03_e.shtml (accessed 2009 Apr. 28).

21. Canadian Institute for Health Information. Average payment per physician report fee-for-service physicians in Canada. Ottawa (ON): The Institute; 2006. Available: http://secure.cihi.ca/cihiweb/products/app_average_payment_per_physician_report 2004 e.pdf (accessed 2009 Feb. 23)

22. Family physicians by sex and age group [questionnaire]. Mississauga (ON): National Physician Survey; 2007. Available: www.nationalphysiciansurvey.ca/nps 12007 Survey/Results/physician2-e.asp (accessed 2009 Feb. 23).

23. Coulthart H. The push to negotiate more MDs for rural Ontario. Natl Rev Med 2004;1. Available: www.nationalreviewofmedicine.com/issue/2004_02_15 /government\&medicine02.html (accessed 2009 Feb. 23)

24. Hutchison B, Birch S, Hurley J, et al. Do physician-payment mechanisms affect hospital utilization? A study of Health Service Organizations in Ontario. CMAJ 1996;154:653-61.

25. Shen J, Andersen R, Brook R, et al. The effects of payment method on clinical decision-making: physician responses to clinical scenarios. Med Care 2004;42:297-302.

26. Bindman AB, Chattopadhyay A, Osmond DH, et al. The impact of Medicaid managed care on hospitalizations for ambulatory care sensitive conditions. Health Serv Res 2005;40:19-38.

27. Landon BE, Zaslavsky AM, Bernard SL, et al. Comparison of performance of traditional Medicare vs Medicare managed care. JAMA 2004;291:1744-52.

28. Lamarche PA, Beaulieu MD, Pineault R, et al. Choices for change: the path for restructuring primary healthcare services in Canada. Ottawa (ON): Canadian Health Services Research Foundation; 2003. Available: www.chsrf.ca/final_research /commissioned_research/policy_synthesis/pdf/choices_for_change_e.pdf (accessed 2009 Feb. 23)

29. Howard M, Goertzen J, Kaczorowski J, et al. Emergency department and walk-in clinic use in models of primary care practice with different after-hours accessibility in Ontario. Health Policy 2008;4:73-88.

30. Chan BTB. The declining comprehensiveness of primary care. CMAJ 2002;166: 429-34.

31. Hutten-Czapski P, Pitblado R, Slade S. Scope of family practice in rural and urban settings. Can Fam Physician 2004;50:1548-50.

32. Ionescu-Ittu R, McCusker J, Ciampi A, et al. Continuity of primary care and emergency department utilization among elderly people. CMAJ 2007;177:1362-8.

33. Haggerty JL, Roberge D, Pineault R. Features of primary healthcare clinics associated with patients' utilization of emergency rooms: urban-rural differences. Health Policy 2007;3:72-85.

Correspondence to: Dr. Richard Glazier, Senior Scientist, Institute for Clinical Evaluative Sciences, Rm. G1-06, 2075 Bayview Ave., Toronto ON M4N 3M5; fax 416 480-6048; rick.glazier@ices.on.ca 